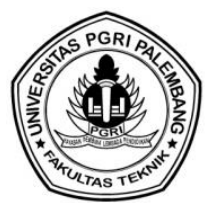

\title{
PERANGKAT NAVIGASI ARAH ANGIN, ARAH KAPAL, DAN KECEPATAN ANGIN UNTUK NELAYAN TRADISIONAL
}

\author{
Albert Gunadhi ${ }^{1}$, Rasional Sitepu ${ }^{2}$, Zein Bilal ${ }^{3}$, \\ Peter R. Angka ${ }^{4}$, Lanny Agustine ${ }^{5}$ \\ 1,2,3,4,5 Jurusan Teknik Elektro, Fakultas Teknik, Universitas Katolik Widya Mandala Surabaya, \\ Jalan Kalijudan no. 37, Surabaya 60114 \\ E-mail: albert@ukwms.ac.id, zein140797@gmail.com
}

\begin{abstract}
ABSTRAKS - Nelayan tradisional memanfaatkan angin darat untuk berlayar pada malam hari, angin darat adalah angin yang berhembus dari daratan ke laut. Pada pagi hari nelayan kembali kedaratan dengan memanfaatkan angin laut. Angin laut adalah angin yang berhembus dari laut ke daratan. Untuk membantu navigasi melaut nelayan tradisional, dibutuhkan sistem pendukung yang dapat mengukur kecepatan angin, arah angin, arah kapal, dan bisa bekerja pada malam hari tanpa sumber listrik dari generator. Alat ini mengukur dengan batas terendah kecepatan angin yang dapat diukur adalah $0,01 \mathrm{~m} / \mathrm{s}$, dan rata-rata kesalahan pengukuran kecepatan angin $0,001 \mathrm{~m} / \mathrm{s}$, sensor pembaca arah angin dapat mengukur dari mana datangnya angin dan arah kapal menuju, serta sistem pembangkit tegangan 12-13,4 Volt DC untuk menyuplai Arduino Uno dan sensor-sensor yang digunakan.
\end{abstract}

Kata kunci: Arduino Uno, Anemometer, HCM5883L, Kompas

\begin{abstract}
S -Traditional fishermen use the land wind to sail at night, land winds are winds that blow from land to sea. In the morning fisherman return to port using sea wind, sea winds are winds that blow from sea to land. To aids traditional fisherman sailing navigation, a instrument measurement that can measure wind speed, wind direction, ship direction, and can work at night without using voltage generator is needed. This measuring instrument can measure wind speed with the lowest speed is $0,001 \mathrm{~m} / \mathrm{s}$, and the average measurment error is $0,001 \mathrm{~m} / \mathrm{s}$, wind direction measurment sensor can measure from whereabouts the wind coming and also measuring whereabouts the ship heading, also have voltage source 12-13,4 Volt DC to supply Arduino Uno and the sensors used at this measuring instrument.
\end{abstract}

Keyword: Arduino Uno, Anemometer, HCM5883L, CompassPendahuluan

\section{PENDAHULUAN}

Untuk mengurangi resiko nelayan tradisional melaut dibutuhkan suatu sistem untuk meningkatkan keamanan berlayar, yaitu sistem untun mengukur arah kapal, arah angin dan kecepatan angin, dengan memanfaatkan sensor anemometer dan sensor kompas digital. kecepatan angin dideteksi menggunakan sensor anemometer dan untuk mengetahui arah angin, dan arah kapal menggunakan sensor digital kompas HCM5883L. Dengan adanya alat ini nelayan dapat mengambil keputusan dalam mengarahkan kemana kapalnya berlayar. Dari latar belakang pembuatan alat ini maka dibuat berberapa rumusan masalah dalam perancangan alat dan pembuatan alat, rumusan masalah adalah membuat suatu sistem pengukuran arah kapal, arah angin, dan pengukuran kecepatan angin. Dengan memanfaatkan Arduino Uno sebagai perangkat pemroses data yang dikirim oleh anemometer, dan sensor pembaca arah angin dengan 
memanfaatkan sensor kompas HCM5883L, membuat sistem pengisian daya baterai 12-13 VDC menggunakan solar panel 100 Wpeak.

\section{TINJAUAN PUSTAKA}

Untuk dapat merealisasikan alat ini maka dibutuhkan dasar-dasar teori untuk menunjang, dasar- dasar teori yang dibutuhkan untuk pembuatan alat ini adalah arduino uno, anemometer, beaufort scale, sensor digital kompas hcm58831, sistem pengisian baterai menggunakan solar panel.

\section{Arduino Uno}

Arduino Uno merupakan sebuah board mikrokontroler yang bersifat open source. Arduino Uno menggunakan mikrokontroler AVR seri ATmega328. Perangkat ini memiliki 14 pin I/O (6 pin diantaranya dapat digunakan sebagai output PWM), 6 pin input analog, koneksi USB, $16 \mathrm{MHz}$ osilator kristal, dan reset. Pin-pin ini berisi semua yang diperlukan untuk mendukung kerja mikrokontroler[1]

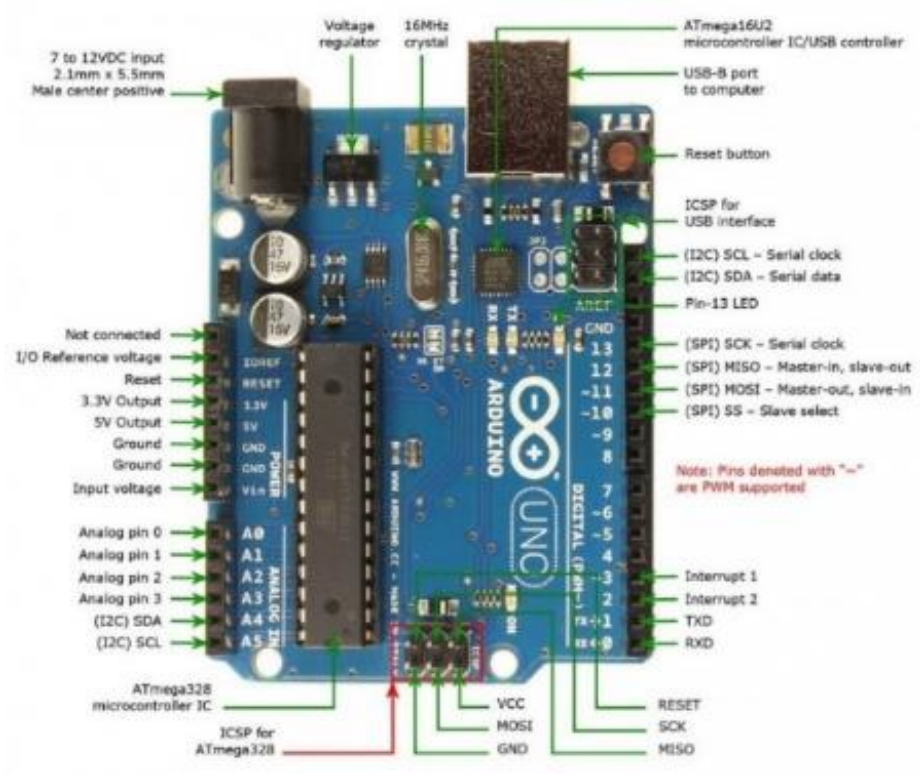

Gambar 1. Arduino Uno R3

Arduino Uno R3 Berfungsi sebagai otak sistem yang berfungsi memproses data yang dikirmkan sensor pada sistem pengukuran alat ini, dan menampilkan data yang diproses melalui LCD 20x4. Data yang ditampilkan pada LCD adalah beufort scale, kecepatan angin dalam satuan $\mathrm{m} / \mathrm{s}$, arah angin dari mana angin datang dan angin menuju, dan kemana arah kapal menuju.

\section{Anemometer}

Anemometer adalah perangkat yang berfungsi untuk mengukur kecepatan angin. Anemometer banyak digunakan di badan meteorologi. Anemometer berasal dari Bahasa Jerman yaitu anemos berarti angin. Anemometer mengukur kecepatan dari angin yang melewati baling baling pada anemometer. pada alat ini akan digunakan cup anemometer. Salah satu tipe anemometer yang memiliki bentuk tiga hingga empat mangkuk hemispherical yang terpasang secara horizontal. Angin yang melewati mangkuk hemispherical pada cup anemometer, Seperti pada Gambar 2 
berputar mangkuknya secara horizontal, putaran ini akan mengukur kecepatan angin dengan perbandingan antara banyaknya putaran dan interval waktu. [2]

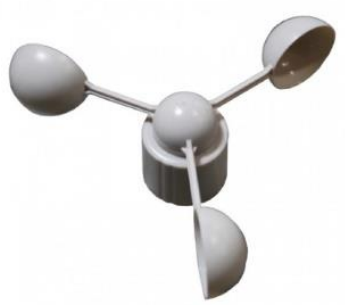

Gambar 2. Cup Anemometer.

Pada cup anemometer terdapat generator yang menghasilkan tegangan ketika anemometer berputar, semakin cepat anemometer berputar pada tabel ini perbandingan kecepatan putaran angin dan listrik yang dihasilkan berikut. Untuk menghasilkan tabel sebagai berikut digunakan formula

$\mathrm{V} \cong 6$ * tegangan

$\mathrm{V}=$ kecepatan angin $(\mathrm{m} / \mathrm{s})$

Tegangan $=$ tegangan output anemometer $(\mathrm{V})$

\section{Beaufort Scale}

Beaufort Scale merupakan suatu pengukuran secara empiris pada pengukuran kecepatan angin di darat mauput di laut. Nama lengkap dari beaufort scale adalah Beaufort wind force scale. Pada alat bantu navigasi pelayaran nelayan tradisional beaufort scale digunakan sebagai pensekala kecepatan angin. Dengan beaufort scale bisa diketahui tingkat bahaya kecepatan angin. Dibawah ini adalah tabel penjabaran nilai dari beaufort scale. Beaufort scale dibagi menjadi 13 tingkatan, sesuai degan tingkat kecepatan angin dan bahaya dari angin yang berhembus.

Tabel 2.2 Beaufort Scale ${ }^{[3]}$

\begin{tabular}{|c|c|l|l|}
\hline Skala & $\begin{array}{c}\text { Kecepatan } \\
\text { angin(m/s) }\end{array}$ & Diskripsi & Efek \\
\hline 0 & 0,447 & Tenang & Tenang dan asap mengarah vertical \\
\hline 1 & $0,447-1,34$ & Udara ringan & Asap mengarah ke arah angin \\
\hline 2 & $1,788-3,12$ & Angin sepoi sepoi & $\begin{array}{l}\text { Angin terasa berhembus dan dedaunan mulai } \\
\text { bergetar }\end{array}$ \\
\hline 3 & $3.57-5,36$ & Angin lembut & Daun mulai bergetar dan bendera berkibar \\
\hline 4 & $5,88-8,04$ & Semilir sedang & Dedaunan dan dahan kecil mulai bergerak \\
\hline 5 & $8,493-10,72$ & Semilir sejuk & Pepohonan kecil mulai berayun \\
\hline 6 & $11,176-13,85$ & Semilir kuat & Dahan besar mulai bergetar \\
\hline 7 & $14,30-16.98$ & angin sedang & $\begin{array}{l}\text { Terasa tekanan saat bergerak melawan arah } \\
\text { angina }\end{array}$ \\
\hline 8 & $17,43-20,56$ & Angin & Dapat mematahkan dahan pohon \\
\hline
\end{tabular}




\begin{tabular}{|c|c|l|l|}
\hline 9 & $21,01-24,14$ & Angin kuat & Kerusakan kecil pada bangunan terutama atap \\
\hline 10 & $24,58-28,16$ & Angin sangat kuat & $\begin{array}{l}\text { Dapat merobohkan pohon dan kerusakan kecil } \\
\text { pada bangunan }\end{array}$ \\
\hline 11 & $28,61-32,18$ & Badai & $\begin{array}{l}\text { Jarang terjadi didarat, dapat menyebabkan } \\
\text { kerusakan besar }\end{array}$ \\
\hline 12 & $32,63<$ & Angin topan & Kuat dan merusak \\
\hline
\end{tabular}

\section{HCM5883L}

Sensor kompas HCM5883L adalah sensor digital pengukuran 3 sudut magnetoresistensif sensor. Sensor ini berukuran kecil, konsumsi daya rendah, akurasi bagus dan berulang, dan toleransi guncangan yang kuat dikuti harga yang terjangkau. Spesifikasi sensor kompas HMC588L[4]

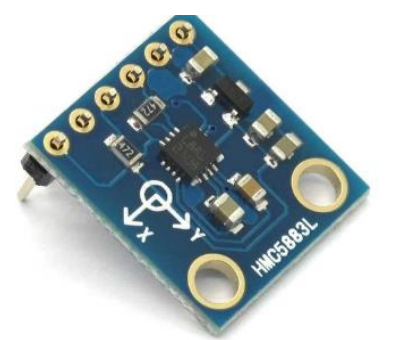

Gambar 3 Bentuk Fisik Sensor kompas HCM5883L

Sensor ini memanfaatkan cara kerja magnetometer arus yang melewati konduktor sehingga bisa didapat medan magnetik disekitarnya. Ketika arus yang melewati konduktor ditempatkan melayang mengalami efek dari medan magnetik bumi, perubahan arah elektron digunakan untuk menentukan arah dari medan magnet. Sensor ini menggunakan ic magnetoresistif yang terbuat dari nikel-besi. Resistansi elektriknya akan berubah sesuai dengan medan magnetiknya. Ketika sensor mengalami perubahan arah maka akan didapat perbedaan tegangan karena perubahan resistansi, perubahan tegangan ini digunakan untuk mendeteksi perubahan arah medan magnet.

\section{Slip Ring}

Slip ring adalah komponen elektronika yang berfungsi untuk mengatasi sambungan elektrik yang memerlukan rotasi $360^{\circ}$ berputar secara penuh, slip ring digunakan pada peralatan elektronik mekanik seperti motor sealing, radar, mikroskop, turbin angin, dan masih banyak lagi. [5]

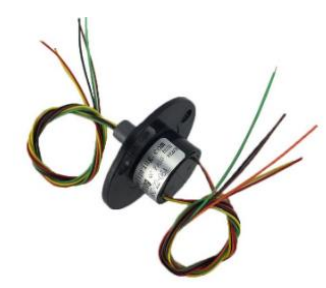

Gambar 4 Bentuk Fisik Slip Ring

\section{Solar Panel}

Solar panel menyerap cahaya matahari untuk menghasilkan listrik memanfaatkan efek photovoltaic. Kebanyakan model dari solar panel menggunakan model wafer dengan bahan 
kristal silikon. Untuk koneksi listrik antar solar panel harus terpasang secara seri. Modul elektrik di solar panel dibuat berdasarkan kebutuhan. Untuk membuat modul dengan tegangan output sesuai dengan kebutuhan maka modul elektrik solar panel akan dibuat seri. Sedangkan untuk membuat modul elektrik yang bisa mengatur arus modul elektrik pada solar panel akan dibuat parallel. [5]

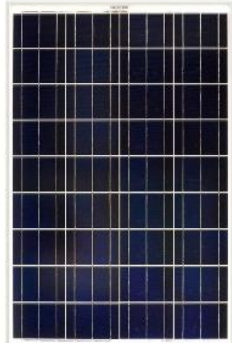

\section{Gambar 5 Solar Panel}

\section{METODE PENELITIAN}

Pada Gambar 6 dapat dilihat bentuk fisik dari perangkat navigasi arah angin, arah kapal, dan kecepatan angin untuk nelayan tradisional. Sistem tersebut dibagi menjadi dua bagian yaitu anemometer dan arah kapal, serta pembaca arah angin. Pada sistem anemometer dan arah kapal menggunakan anemometer SKU SEN0170 sebagai sensor kecepatan angin dan HCM5883L sensor kompas digital sebagai pembaca arah kapal. Data yang didapat dari dua sensor tersebut diolah Arduino Uno data yang diolah ini ditampilkan pada LCD 20x4. Sistem kedua yaitu pembaca arah angin, sistem ini memanfaatkan sensor digital kompas HCM5883L untuk membaca dari mana arah angin datang sensor ini kemudian dipasang pada penujuk angin. Untuk menghubungkan sensor HCM5883L dengan Arduino Uno digunakan slip ring, slip ring bertugas sebagai konektor yang bisa berputar $360^{\circ}$ tanpa merusak kabel. Data yang didapat oleh sensor HCM5883L diproses Arduino Uno, data yang telah diproses Arduino Uno akan ditampilkan pada LCD 16x2. sebagai Sumber daya pada kedua sistem ini menggunakan baterai $13 \mathrm{~V} 23 \mathrm{Ah}$. Baterai tersebut bisa di isi dayanya dengan menggunakan solar panel.

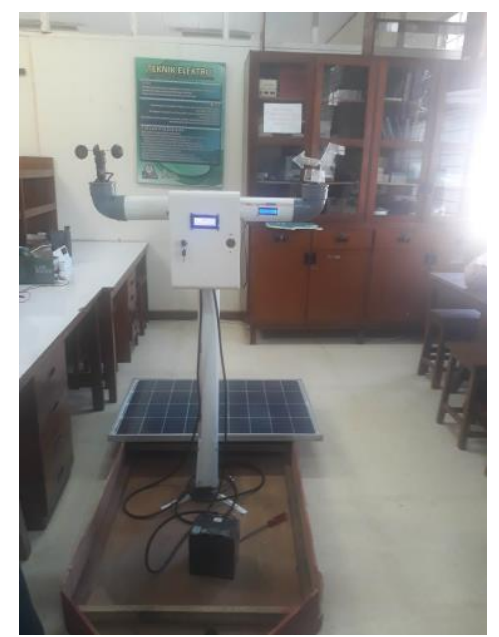

Gambar 6. Bentuk fisik dari perangkat navigasi arah angin, arah kapal, dan kecepatan angin untuk nelayan tradisional. 
Untuk membentuk sistem ini dibutuhkan port SCL dan SDA Arduino Uno sebanyak 3 pasang sedangkan untuk satu Arduino Uno hanya ada 2 pasang port SCL dan SDA. Untuk penunjuk mata angin digunakan satu sensor kompas HCM5883L dan untuk penunjuk arah kapal digunakan 1 sensor HCM5883L. Sehingga keseluruhan komponen yang digunakan pada sistem ini adalah 2 Arduino Uno, 2 sensor HCM5883L, 1 sensor anemometer, 1 slip ring, 1 LCD 20x4, 1 LCD 16x2, 1 baterai 12VDC, 1 solar panel 100W dan 1 solar charger controller.

Gambar 7 menunjukkan diagram blok sensor anemometer dan sensor HCM5883L menggunakan baterai sebagai sumber dayanya, baterai yang digunakan memiliki tegangan sebesar 13,6 - 13,8 VDC dengan kapasitas 28 Ah. Baterai digunakan mensuplai tegangan Arduino Uno, sensor HCM5883L, LCD 20x4 dan sensor anemometer. Pada saat pagi hari daya baterai bisa diisi menggunakan panel surya 100 Watt. Saat angin berhembus melewati cup anemometer, cup berputar dan menghasilkan tegangan yang dibaca oleh Arduino pin A1 untuk mendapatkan nilai kecepatan angin. Setelah nilai kecepatan angin didapatkan, nilai ditampilkan pada LCD 20x4.

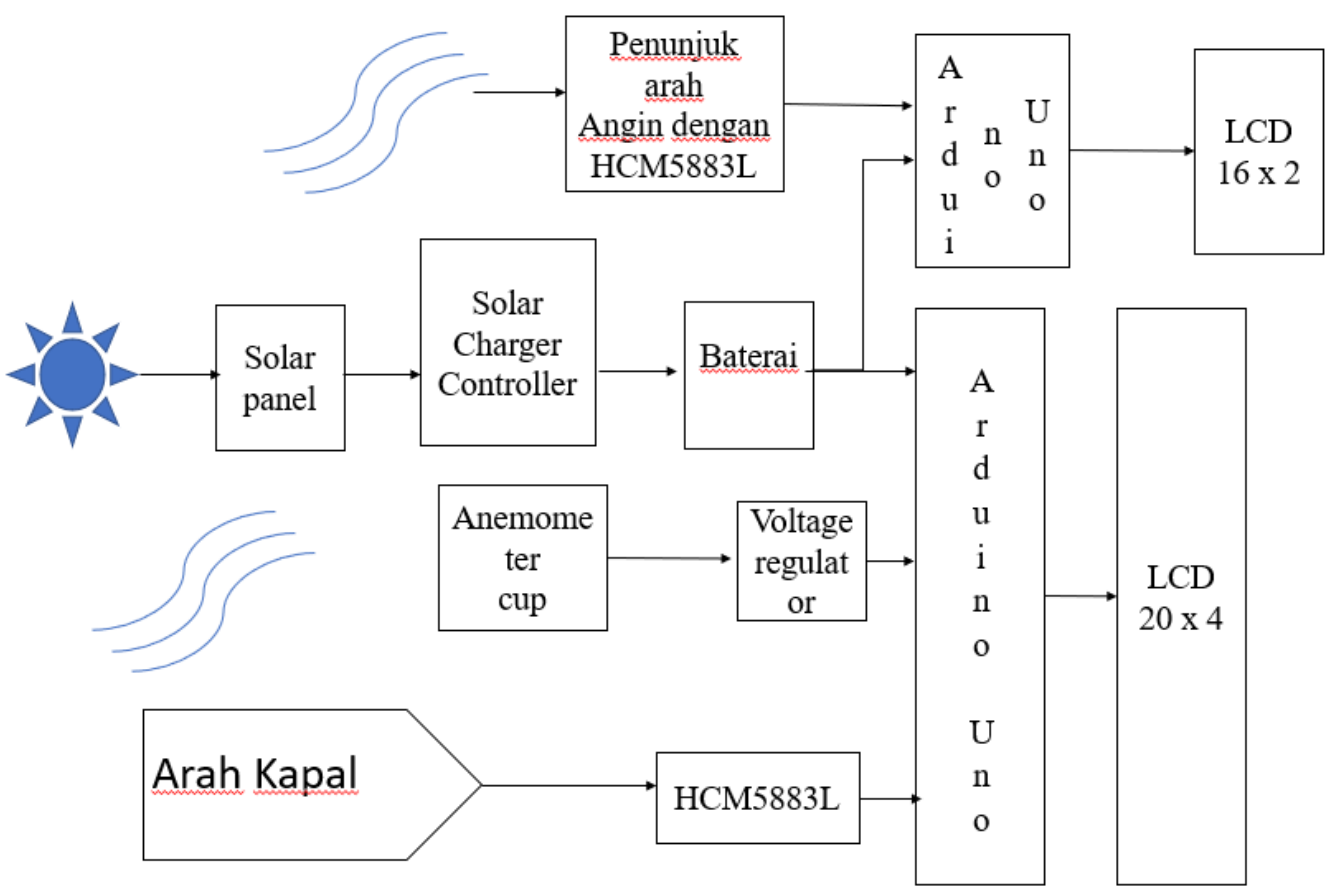

Gambar 7. Diagram Blok sensor anemometer untuk pembacaan kecepatan angin, Sensor HCM5883L untuk pembacaan arah kapal, dan Sensor HCM5883L untuk pembacaan arah angin

Arah dari kapal didapatkan menggunakan sensor HCM5883L yang terpasang pada panel alat dan diarahkan ke haluan kapal. Sensor HCM5883L memberi data ke Arduino ke arah mata angin mana kapal menghadap, data ini kemudian ditampilkan pada LCD 20x4. pembaca arah angin menggunakan sensor HCM5883, alat pembaca arah angin ini menggunakan empat komponen untuk berkerja yaitu sensor HCM5883L, penunjuk arah angin, dan Arduino Uno. Saat angin berhembus mengenai penunjuk arah angin, penunjuk arah angin berputar menuju ke arah angin datang.

Arah dari kapal didapatkan menggunakan sensor HCM5883L yang terpasang pada panel alat dan diarahkan ke haluan kapal. Sensor HCM5883L memberi data ke Arduino ke arah mata angin mana kapal menghadap, data ini kemudian ditampilkan pada LCD 20x4. pembaca arah angin menggunakan sensor HCM5883, alat pembaca arah angin ini menggunakan empat komponen untuk berkerja yaitu sensor HCM5883L, penunjuk arah angin, dan Arduino Uno. 
Saat angin berhembus mengenai penunjuk arah angin, penunjuk arah angin berputar menuju ke arah angin datang.

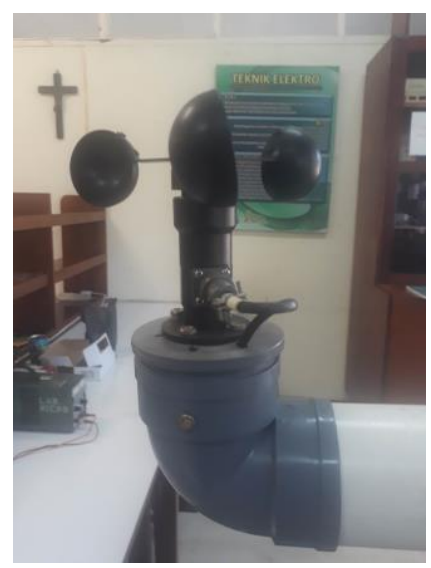

(a)

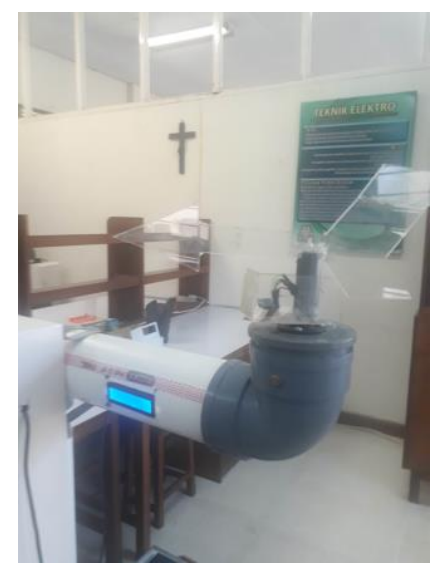

(b)

Gambar 8.(a) Sensor anemometer (b) Sensor pengukur arah angin

Penunjuk arah angin menujukkan arah angin datang dengan menggunakan sensor HCM5883L, sensor HCM5883L menunjukkan kemana arah angin datang sesuai arah dari penunjuk arah angin data yang didapat ini akan dilewatkan konektor slip ring, slip ring berfungsi sebagai konektor yang bisa berputar $360^{\circ}$. Kemudian data diproses oleh Arduino Uno. Data yang didapat Arduino Uno dari sensor HCM5883L ditampilkan pada LCD 16x2. Suplay tegangan sistem ini didapat dari baterai 13VDC.

\section{HASIL DAN PEMBAHASAN}

Dari sistem yang sudah dibuat dilakukan berberapa percobaan untuk mengetahui apakah sistem dapat bekerja dengan baik atau tidak. Pengujian dilakukan dengan cara memberikan sumber angin ke sistem anemometer dan membandingkannya dengan alat ukur anemometer yang dapat mengukur dengan baik. Memberi sumber angin ke pengukur arah angin dan membandingkan hasil pengukuran dengan kompas untuk mengetahui apakah sistem sudah dapat mengukur arah mata angin dengan seharusnya. Sistem pengukuran kecepatan angin, arah angin dapat berkerja dengan baik tanpa mempedulikan kemana kapal menghadap dan juga akan diberikan kemiringan sebesar $5^{\circ}$, untuk menguji apakah sistem dapat digunakan pada pelayaran nelayan tradisional. Berikut ini adalah tabel dari hasil percobaan yang telah dilakukan.

Tabel 2 Pengukuran kecepatan angin

\begin{tabular}{|c|c|c|}
\hline No & $\mathbf{v A 0}(\mathbf{m} / \mathbf{s})$ & $\mathbf{v A 1}(\mathbf{m} / \mathbf{s})$ \\
\hline 1 & 0,019 & 0,02 \\
\hline 2 & 0,42 & 0,46 \\
\hline 3 & 1,40 & 1,42 \\
\hline 4 & 1,70 & 1,75 \\
\hline 5 & 2,08 & 2,09 \\
\hline 6 & 1,43 & 1,45 \\
\hline 7 & 1,40 & 1,42 \\
\hline 8 & 1,86 & 1,85 \\
\hline 9 & 1,97 & 2,05 \\
\hline
\end{tabular}




\begin{tabular}{|l|l|l|}
\hline 10 & 2,19 & 2,20 \\
\hline 11 & 2,70 & 2,75 \\
\hline 12 & 2,96 & 2,95 \\
\hline
\end{tabular}

Dari tabel tersebut didapat bahwa pengukuran kecepatan angin oleh anemometer pada sistem ini dan anemometer alat ukur dapat melakukan pengukuran yang serupa.

Tabel 3 Pembandingan arah angin dan arah kapal dengan kompas dimana arah kapal menuju Timur

\begin{tabular}{|c|c|c|c|}
\hline No & Arah Angin & Arah Penunjuk & Arah Kompas \\
\hline $\mathbf{1}$ & Barat & Barat & Barat \\
\hline $\mathbf{2}$ & Barat daya & Barat Daya & Barat Daya \\
\hline $\mathbf{3}$ & Selatan & Selatan & Selatan \\
\hline $\mathbf{4}$ & Tenggara & Tenggara & Tenggara \\
\hline $\mathbf{5}$ & Timur & Timur & Timur \\
\hline $\mathbf{6}$ & Timur Laut & Timur Laut & Timur Laut \\
\hline $\mathbf{7}$ & Utara & Utara & Utara \\
\hline $\mathbf{8}$ & Barat daya & Barat Daya & Barat Daya \\
\hline $\mathbf{9}$ & Barat Laut & Barat Laut & Barat Laut \\
\hline
\end{tabular}

Dari tabel 3 didapatkan bahwa pengukur arah angin dapat berkerja dengan baik dimana pengukur arah angin dapat membaca arah dari mata angin sesuai dengan kompas.

Tabel 4 . Pengukuran Kecepatan angin, arah angin dengan sumber angin bebas dan kemiringan kapal $5^{\circ}$

\begin{tabular}{|c|c|c|c|c|c|}
\hline No & Arah Angin & Arah Kapal & Arah Kompas & Kecepatan Angin A0 & $\begin{array}{c}\text { Kecepatan Angin } \\
\text { A1 }\end{array}$ \\
\hline $\mathbf{1}$ & Barat & Timur Laut & Barat & 0,4 & 0,38 \\
\hline $\mathbf{2}$ & Timur & Timur & Timur & 0,09 & 0,1 \\
\hline $\mathbf{3}$ & Timur & Timur & Timur & 1,50 & 1,54 \\
\hline $\mathbf{4}$ & Timur & Timur & Timur & 1,78 & 1,70 \\
\hline $\mathbf{5}$ & Tenggara & Timur & Timur & 0,09 & 0,1 \\
\hline $\mathbf{6}$ & Selatan & Timur & Selatan & 0,19 & 0,20 \\
\hline $\mathbf{7}$ & Selatan & Timur & Selatan & 0,69 & 0,70 \\
\hline $\mathbf{8}$ & Tenggara & Timur & Timur & 0,79 & 0,1 \\
\hline $\mathbf{9}$ & Tenggara & Timur & Tenggara & 0,09 & 0,93 \\
\hline $\mathbf{1 0}$ & Tenggara & Timur & Tenggara & 0,96 & 1,0 \\
\hline $\mathbf{1 1}$ & Timur & Timur & Timur & 0,96 & 0,7 \\
\hline $\mathbf{1 2}$ & Timur & Timur & Timur & 0,73 & \\
\hline
\end{tabular}

Dari pengukuran yang telah dilakukan sensor anemometer, sensor pembaca arah angin, dan sensor pembaca arah kapal dapat mengukur dengan baik meski terjadi kemiringan pada sensor sehingga pengukuran digunakan pada kapal sesunguhnya dapat dilakukan

\section{KESIMPULAN}

Batas terendah kecepatan angin yang dapat diukur adalah $0,01 \mathrm{~m} / \mathrm{s}$. Rata rata kesalahan pada pengukuran kecepatan angin adalah $0,01 \mathrm{~m} / \mathrm{s}$. Pembacan datangnya arah angin tidak terpengaruh oleh posisi kapal. Sehingga dapat disimpulkan alat dapat bekerja dengan baik.

\section{DAFTAR PUSTAKA}

[1] Mikrokontroler Arduino Uno, 
Datasheet(https://components101.com/microcontrollers/arduino-uno (diakses tanggal 12 November 2018)

[2] Dines, William henry, "anemometer", encyclopedia britannica, 1911(https://www.britannica.com/technology/anemometerht, diakses tanggal 7 November 2018)

[3] CS Rangan, GR Sarma, VSV Mani, Instrumentation Device and system, Tata McGrawhill publishing company

[4] Oliver, John E, Encyclopedia Of World Climatology, Van Nostrand Reinold, 2015,156

[5] Sauicer, Walter J, Principle of meterological analysis, Courir corporation, 2003

[6] HCM5883L -Datasheet(https://cdn-shop.adafruit.com/datasheets/HMC5883L_3Axis_Digital_Compass_IC.pdf Diakses tanggal 13 februari 2019)

[7] Slip ring-Datasheet (www.eslipring.com/en/productinfo_101.html) 